\title{
Retraction Note: Monitoring of ocean surface circulation and swimming athletes' physical training data based on loT perception
}

\section{Fengbin $\mathrm{Wu}^{1}$}

Published online: 4 November 2021

(c) Saudi Society for Geosciences 2021

Retraction Note: Arabian Journal of Geosciences (2021) 14: 1479 https://doi.org/10.1007/s12517-021-07835-4

The Editor-in-Chief and the Publisher have retracted this article because the content of this article is nonsensical. The peer review process was not carried out in accordance with the Publisher's peer review policy. The author has not responded to correspondence regarding this retraction.

The original article can be found online at https://doi.org/10.1007/ s12517-021-07835-4.

Fengbin $\mathrm{Wu}$

fengbin@ccit.js.cn

1 Changzhou College of Information Technology,

Changzhou 213164, China 